\title{
A LITERATURA NATIVA DE OLÍVIO JEKUPÉ: CONHECENDO OUTROS MUNDOS
}

\author{
Célia Regina Delácio Fernandes* \\ Sonia Ferreira dos Santos Troquez**
}

\begin{abstract}
RESUMO: Este artigo socializa uma reflexão sobre a literatura escrita pelo indígena e sua importância na escola, tendo como objetivo conhecer duas obras de literatura nativa infantojuvenil do escritor Olívio Jekupé: O saci verdadeiro (2002) e Ajuda do Saci Kamba'i (2006). Utilizou-se o termo literatura nativa, criado pelo referido escritor da comunidade Guarani, para dirigir-se aos textos escritos pelos indígenas, ao narrarem sobre seus povos, suas culturas e saberes. $O$ recorte temático baseou-se na necessidade de abordar a literatura nativa infantojuvenil, por se considerar relevante a contribuição para a divulgação da cultura dos povos originários no ambiente escolar, pois falar para crianças e jovens desse assunto é adentrar em um universo desconhecido para muitos professores. Com o advento da Lei $n .^{\circ}$ 11.645/2008 (BRASIL, 2008), que instituiu a obrigatoriedade do estudo de história e das culturas afro-brasileira e indígena nas instituições de ensino, a temática indígena passou a ocupar mais espaço no âmbito escolar, carecendo de materiais literários e pedagógicos para a abordagem desse conteúdo. Os fundamentos teóricos se apoiam em pesquisadores da literatura indígena brasileira contemporânea, a saber: Almeida e Queiroz (2004), Dorrico (2020), Graúna (2013), Jekupé (2009), dentre outros.
\end{abstract}

ABSTRACT: This article socializes a reflection about the literature written by indigenous and its importance at school; with the objective of knowing two children and youth's native literature works by the writer Olivio Jekupé: "O Saci Verdadeiro" (2002) and "Ajuda do Saci Kamba'i”" (2006). Using the term native literature created by the aforementioned writer from the Guarani community to present texts written by the indigenous, narrating about their peoples, cultures and knowledge. The thematic approach was based on the need to convey the children and youth's native literature, considering the relevant contribution to the culture's dissemination of native peoples in the school environment, because to talk with children and young people about this subject is to enter an unknown universe for many teachers. With the advent of Law no. 11.645/2008 (BRASIL, 2008), which instituted the mandatory study of Afro-Brazilian and Indigenous history and cultures in educational institutions, the indigenous theme began to occupy more space at the school environment, requiring literature and pedagogical materials in order to approach this content. The theoretical foundations are supported by researchers of the Contemporary Indigenous Brazilian Literature, knowing: Almeida and Queiroz (2004), Dorrico (2020), Graúna (2013), Jekupé (2009), among others.

PALAVRAS-CHAVE: Literatura nativa; literatura infantojuvenil; indígena; Olívio Jekupé.

KEYWORDS: Native literature; Children and youth's literature; Indigenous; Olivio Jekupé.

\section{INTRODUÇÃO}

A criação da Lei n. ${ }^{\circ} 11.645$, de 10 de março de 2008 (BRASIL, 2008) possibilitou uma aproximação com as culturas tradicionais indígenas, tornando-as conhecidas pela sociedade brasileira e contribuiu com a autoestima desses povos ao oferecer-lhes uma educação diferenciada. Nessa perspectiva, este artigo pretende colaborar com a INTERLETRAS, ISSN No 1807-1597. V. 9, Edição número 34. Outubro, 2021/ Março de 2022- p

Dossiê: Educação, infância, diversidade e ensino de língua em contexto complexo. 
divulgação da literatura escrita pelos povos indígenas, por entender a importância da literatura nativa (JEKUPÉ, 2009), especialmente a infantojuvenil, que necessita ser trabalhada nas escolas tanto indígenas como não indígenas, pois trazem um rico repertório de modos de vida, manifestações culturais e cosmovisões desses povos.

Vale ressaltar que a literatura nativa evidencia a relevância da escrita dos povos indígenas, visto que eles têm usufruído dessa ferramenta na divulgação de seus conhecimentos. De fato, a literatura nativa apresenta-se como uma proposta de reflexão a respeito das narrativas produzidas por autores indígenas e de seus saberes nas escolas do ensino fundamental.

Ao se explicitar o termo literatura nativa, demonstra-se o valor para os indígenas de serem identificados por uma literatura que os represente. A literatura nativa é um conceito elaborado por Olívio Jekupé (2009), com a intenção de marcar e diferenciar a literatura escrita pelos povos indígenas, pois cada etnia tem suas tradições, narrativas e culturas próprias, a exemplo dos Guarani e Munduruku.

Desse modo, a literatura nativa objetiva desconstruir estereótipos há muito tempo construídos em relação aos povos indígenas, e rotineiramente utilizados por parte da população brasileira pelo desconhecimento da diversidade, riqueza cultural dessas comunidades e de sua relevante contribuição na formação da sociedade. Considera-se que as histórias escritas por eles propiciam o conhecimento das diferentes etnias, trazendo a inclusão e o respeito aos povos originários.

Embora tenha sido um avanço para os indígenas terem seus direitos garantidos e sua literatura publicada, há uma grande dificuldade em reconhecer tais direitos. Existem lacunas que precisam ser preenchidas como, por exemplo, a escassez de materiais para trabalhar a temática indígena nas escolas e na formação de professores indígenas. Nesse sentido, este trabalho centra-se na reflexão sobre a literatura nativa infantojuvenil na tentativa de ampliar o conhecimento sobre as culturas dos povos originários na escola indígena e não indígena a fim de atingir o público leitor desde a sua infância.

Dessarte, as obras de literatura infantojuvenil de autoria nativa cumprem o seu papel ao divulgarem o modo de ser e pensar dos povos indígenas, valorizando a sua forma de vida, de maneira que reconhecem a sua importância, pois elas trazem o conhecimento de textos literários com temas a serem usados em sala de aula, que visam reforçar a inclusão e valorização dessas culturas.

Sendo assim, este estudo apresenta a convivência entre mundos distintos autorepresentados nas obras de autoria indígena, considerando a contribuição da literatura infantojuvenil ao evidenciar as culturas desses povos. Nessa perspectiva, selecionou-se duas obras de Olívio Jekupé: Ajuda do Saci Kamba’i (2006) e O saci verdadeiro (2002).

\section{O SACI INDÍGENA DE OLÍVIO JEKUPÉ}

INTERLETRAS, ISSN N $N^{\circ}$ 1807-1597. V. 9, Edição número 34. Outubro, 2021/ Março de 2022- p

Dossiê: Educação, infância, diversidade e ensino de língua em contexto complexo. 
Esse mundo do indígena povoado de seres, espíritos e saberes pode ser contemplado nas obras de Jekupé, na figura do Saci-Pererê, apresentado como um ser espiritual, protetor da floresta, o qual se propõe a resolver as causas impossíveis, sendo esta uma de suas virtudes. Isto posto, as obras Ajuda do Saci Kamba'i (2006) e O saci verdadeiro (2002), de Jekupé, exibem histórias de um personagem mítico da cultura Guarani, conhecido no folclore brasileiro como uma lenda, e para os indígenas como o "mito do Saci-Pererê".

Os mitos fazem parte da cultura indígena e são uma maneira de manter e propagar as narrativas essenciais para essa comunidade, que eram repassadas apenas oralmente.

[...] o mito é como a representação concreta da concepção do mundo de comunidades humanas. Dessa forma, a tradição mítica de cada povo constitui um esforço no sentido da representação de si próprio, do que é, do que faz, de como vive, e do estabelecimento de toda uma moral, um ritual, uma mentalidade, baseando-se nessa mitologia. A função social do mito, porém, não exclui a sua função poética ou recreativa (ALMEIDA; QUEIROZ, 2004, p. 233).

Com efeito, ao divulgarem os mitos de forma escrita, os escritores indígenas materializam seu mundo de saberes e crenças. Ao fazerem isso, eles ocupam o seu lugar de fala individual, coletivo e político, tornam-se autores de suas narrativas, e estão representados a partir da voz do indígena, e não pela voz do Outro. Tais mitos permanecem vivos nas florestas e aldeias, e na atualidade estão sendo transmitidos por meio de livros publicados pelos indígenas.

Devido à importância dessas narrativas para os indígenas, Jekupé (2002, 2003, 2006, 2009) entende a necessidade de perpetuá-las, compartilhando esse universo de conhecimentos e seres míticos em suas obras. Os mitos, que anteriormente eram repassados às gerações vindouras, por meio da oralidade, são recriados por Jekupé, que lhes confere valor literário e estético, transformando-os em livros e, com isso, permite que muitos indígenas e não indígenas tenham acesso a essas histórias.

Ao divulgar os mitos de sua cultura Guarani, Jekupé (2002, 2003, 2006, 2009) manifesta o respeito ao seu povo, a relevância dos anciãos, a sabedoria dos antepassados e a confiança em seus ensinamentos, pois os guardiões são uma fonte de saber. Esse mundo mítico e mágico, descrito por Jekupé (2006) em suas obras, está representado por um personagem mítico encontrado por ele, o Saci-Pererê, que saiu das aldeias e do imaginário Guarani para ser conhecido pelos demais brasileiros através da literatura.

Tal personagem mítico, o Saci, tem a invisibilidade como um dos seus atributos, porque ele pode estar em todo lugar sem ser visto. Ele é um espírito da floresta, um guardião das matas. O Saci é imortal e sempre está por perto observando a todos e, quando precisam de sua ajuda, ele aparece para aqueles considerados bons, mas muitos não podem vê-lo e talvez nunca o verão, porém acreditam em sua existência. Este Saci é diferente do conhecido pela maioria dos brasileiros, pois o fato de ser um indígena possui uma representação da cultura e etnia Guarani no personagem. 
Descrever esse personagem tão conhecido, o Saci, inspira e remete à infância de muitas crianças no Brasil, por ele ser uma das figuras sempre lembradas na época de comemorações do folclore nas escolas. Narrado por Jekupé (2009), ele está sendo apresentado aos brasileiros em uma versão diferente da conhecida tradicionalmente nas histórias de Monteiro Lobato. Jekupé (2009, p. 27) define seu personagem da seguinte maneira:

[...] tem duas pernas e não usa carapuça. O que lhe dá poderes é um colar chamado Baêta. É uma entidade da floresta que ajuda os homens e ao contrário do que diz Monteiro Lobato - que ele não morre de sete em sete anos para que um novo Saci nasça no taquaral - ele não morre nunca".

Dessa maneira, os Guarani acreditam nos poderes do Saci, porém, esse ser espiritual não gosta de andar ou falar com pessoas ruins, prefere ficar no anonimato, pois teme que o bastão com poderes possa ser roubado e utilizado para fazer o mal. Ao abordar esse mundo mítico e mágico e seus personagens, Jekupé (2002) fez uma grande descoberta: o Saci-Pererê indígena, diferente do conhecido no Brasil.

Nas obras O saci verdadeiro (JEKUPÉ, 2002) e Ajuda do Saci Kamba 'i (JEKUPÉ, 2006), os seus respectivos personagens, Vera e Karaí, apresentam algo em comum: são crianças pertencentes à etnia Guarani, possuem o desejo de estudar e, para isso, precisam deslocarse à cidade para frequentar uma escola e aprender a escrita; por fim, deparam-se com situações inusitadas que dificultam esse processo rumo à sua realização. Tal problemática leva-os ao encontro de um ser espiritual, visto como um indivíduo com poder para ajudálos a resolver seus dilemas.

O livro Ajuda do Saci Kamba'i possui nove episódios: O sonho de Vera; Visita à aldeia; De volta à cidade; Férias na aldeia; A avenida; No hospital; Más notícias; A triste ida à cidade; Kamba'i e, no final desses episódios, consta a tradução da história em Guarani: Kamba'i nhopytyvõ a regua. Trata-se da história de um menino cujo nome é Vera, apresentado por Jekupé (2006) como "índio" Guarani, que deseja estudar na cidade para obter o conhecimento dos não indígenas. Os pais de Vera temem por seu filho, mas fazem a sua vontade, mesmo sabendo dos perigos da vida na cidade.

Já na obra $O$ saci verdadeiro (2002), a mãe de Karaí faz a intermediação entre as narrativas dos seus antepassados e o menino, pois sempre lhe contava histórias, e uma das mais apreciadas pela criança era a do Saci-Pererê. Desse modo, Karaí passa a frequentar a escola, com o desejo de aprender a escrever para um dia poder registrar as histórias narradas por sua mãe.

Tais obras possuem traços da oralidade utilizada por Jekupé $(2002,2003,2006,2009)$ ao descrever sua cultura e tradição. A relação entre a oralidade e a literatura escrita é uma peculiaridade da prática escritural indígena, bem como a ancestralidade e identidade de seu povo Guarani. Dessa maneira, ao escrever as histórias do personagem Saci, Jekupé (2002) revive na memória as narrativas relatadas pelo povo Guarani, transmitidas 
oralmente pelos mais velhos aos mais jovens da aldeia para que não se percam com o tempo.

Ao fazer isso, Jekupé (2002) valoriza a sua identidade e a de seu povo ao mostrar o cotidiano dos indígenas, as suas experiências, pois é neste encontro com o passado e na convivência com os guardiões que estão os acervos das histórias dessas pessoas, guardados na memória de seus integrantes. Portanto, é por meio das sociedades orais que as sabedorias dos indígenas são perpetuadas por gerações.

Segundo Dorrico (2020), para Jekupé, as histórias sobre o personagem Saci não são folclóricas, são verdadeiras, e para os Guarani são reais, por isso ele acredita ser importante as crianças indígenas conhecerem-no. Os Guarani acreditam nos poderes do Saci, pois ele não gosta de se aproximar de indivíduos ruins e teme pelo possível uso inadequado do bastão, caso seja roubado.

A narrativa, tomada como literatura por Jekupé, designa-se como histórica. Esta literatura histórica justifica a ancestralidade como ponto de partida para dar-se a conhecer o modo de vida e cultura do povo guarani. Da mesma forma, ela pode ser percebida como promoção desse conhecimento ancestral, cultural e comunitário (DORRICO, 2018, p. 127).

Jekupé $(2002,2006)$ faz a interação entre os dois mundos: o do indígena e do não indígena, o espiritual e o físico, ao tratar de temáticas polêmicas, de preconceitos e estereótipos, trazendo os temas para uma possível discussão em sala de aula. A interculturalidade e os preconceitos enfrentados pelos indígenas na escola estão presentes nas duas obras protagonizadas por indígenas: O saci verdadeiro (JEKUPÉ, 2002) e Ajuda do Saci Kamba ’i (JEKUPÉ, 2006).

\section{A PRESENÇA DA ESCOLA EM AJUDA DO SACI KAMBA'I (2006) E O SACI VERDADEIRO (2002)}

A escola, tema presente nos discursos de Jekupé, está dentro de suas obras, com personagens que se misturam com desejos e angústias do próprio autor. "Como hoje temos escolas nas aldeias do Brasil é bom porque podemos continuar contando e ao mesmo tempo registrando essas histórias sobre ele, inclusive os jurua kuery (não índios)" (JEKUPÉ, 2009, p. 16).

Em suas obras, Jekupé (2002, 2003, 2006, 2009) evidencia a importância da escola, como foi para ele e tem sido para o seu povo, pois, ao aprender a ler e a escrever, pode divulgar a verdadeira história dos povos indígenas, usando toda a sua criatividade e sabedoria. Trata-se da experiência específica do indígena, em que Jekupé $(2002,2006)$ apresenta o processo de interação entre diferentes grupos na escola não indígena. Dessa forma, voltase para suas origens, e encontra meios para resistir às discriminações na convivência com o Outro.

INTERLETRAS, ISSN $N^{\circ}$ 1807-1597. V. 9, Edição número 34. Outubro, 2021/ Março de 2022- p

Dossiê: Educação, infância, diversidade e ensino de língua em contexto complexo. 
As histórias analisadas refletem o orgulho do autor de ter realizado seu sonho de se tornar um escritor e transmitir aos seus parentes a necessidade da instituição escolar, sendo ela um instrumento para valorização de seus saberes. Essa preocupação de Jekupé (2002, 2003, 2006, 2009) está refletida em suas narrativas, à medida que os personagens desejam conhecer a escrita, seguindo o mesmo caminho, divulgando as suas tradições, por meio das histórias escritas por eles.

Conforme Mancini e Troquez (2009), a história demonstra que os povos originários têm sinalizado, de forma acentuada, o modo como são vistos e retratados em nosso país. Ao ler textos de literatura nativa na escola, é possível refletir a respeito de preconceitos sofridos pelo indígena nos espaços onde parece inconcebível que eles aconteçam, ou seja, nos ambientes educativos, onde deveriam ter o livre acesso e o direito de manifestaremse culturalmente, sem estereótipos.

Nesse sentido, a literatura nativa vai em uma direção oposta, ao trazer visibilidade aos povos originários frente a sociedade via literatura escrita pelo próprio indígena. Ao abordar a pluralidade e a diversidade, abre-se caminho para desconstrução de conceitos errôneos perpetuados por tantos séculos. Com efeito, a instituição educacional tem um papel importante no combate aos preconceitos e discriminações.

Além disso, as obras de Jekupé (2002, 2003, 2006, 2009) manifestam a vontade de ter reconhecidos seus saberes e a ascendência de seu povo. Também expõem esse caráter militante, uma vez que servem como uma "arma de defesa" do indígena (JEKUPÉ, 2009, p. 13). Jekupé (2009) talvez tenha escrito com a intenção de apontar a possibilidade de convivência mais harmoniosa entre mundos diferentes, mas sem a intenção de tornar o outro igual e, sim, ver nessas diferenças a oportunidade de aprendizado, ao compartilhar seus conhecimentos.

Conforme Mindlin (2002), Jekupé (2002) busca fazer interação entre uma sociedade e outra. Assim, esses relatos utilizam dois mundos diferentes: o do indígena e do não indígena, porque pretendem expor um caráter educativo e conciliador ao mostrar uma convivência saudável e construtiva entre universos distintos, mantendo os saberes aprendidos pelos antepassados.

Nesta experiência libertadora em que os protagonistas têm necessidade de conhecer o outro, se desprendendo de preconceitos, vivenciando um processo de conhecimento de diferentes culturas, de outros costumes, ao mesmo tempo os possibilita conhecerem-se mais. Nas duas obras, Jekupé $(2002,2006)$ exemplifica maneiras como a escola não indígena acolhe esses povos, a fim de desconstruir uma imagem veiculada de discriminações, as quais foram construídas socialmente em torno desses sujeitos.

Desse modo, ao apresentar a convivência dos personagens Karaí e Vera com a instituição de ensino, Jekupé $(2002$, 2006) divulga a importância da interculturalidade e aborda as dificuldades no convívio com culturas, pensamentos e comportamentos variados.

INTERLETRAS, ISSN No 1807-1597. V. 9, Edição número 34. Outubro, 2021/ Março de 2022- p

Dossiê: Educação, infância, diversidade e ensino de língua em contexto complexo. 
É importante que todos saibam que na aldeia Krucutu, onde moro, todos falam a língua nativa, desde as crianças até os mais velhos. Toda a cultura e tradição continuam sendo ensinadas pelos mais velhos porque eles têm muita experiência. São professores, mesmo não sabendo ler ou escrever, pois são mestres na prática e guardam uma sabedoria que vem de muito antigamente (JEKUPÉ, 2003, p. 6).

Jekupé (2003) usa como referência a sua vida na aldeia e sua experiência, a fim de mostrar como mantém vivos seus saberes, valorizando os ensinamentos transmitidos pelos mais velhos, chamados por ele de mestres, e estes são repassados aos seus integrantes jovens e crianças e, mesmo sem a escrita, permanecem vivos até hoje em suas memórias.

Para Lisbôa (2015, p. 44), "essa constância dos atravessamentos de fronteiras, dos trânsitos e das circulações, temas caros à intermediação cultural, aproxima a condição de Jekupé à condição de personagens míticos que perfazem a intermediação entre mundos, [...]". O personagem Vera faz esse percurso ao sair de sua casa na aldeia para ir para um mundo diferente.

Em Ajuda do Saci Kamba'i (JEKUPÉ, 2006) é possível inferir que o personagem Vera possui um breve conhecimento sobre o não indígena, sabe o que é uma escola na cidade e manifesta a vontade de fazer parte desse universo a fim de realizar seu objetivo: o de aprender a escrita. "Vera era um indiozinho de 7 anos que sonhava em estudar na cidade e ter também o conhecimento dos Jurua. Vera acreditava que, aprendendo a ler e a escrever na língua portuguesa, poderia ajudar a defender seu povo" (JEKUPÉ, 2006, p. $7)$.

A realidade do personagem é algo que acontece e, talvez, muitos indígenas precisem passar pelo mesmo processo, de sair de sua comunidade para estudar em unidades educacionais fora da aldeia; alguns por estarem já vivendo nos centros urbanos, e outros por não terem outra opção, como no caso de Vera. Essa vontade de frequentar uma escola não indígena, com pessoas de outra comunidade (a cidade), força o personagem a sair de seu mundo, seu lugar de origem.

Alguns indígenas fizeram e fazem essa opção de sair de seu lugar de origem em busca de mais conhecimento. Muitos deles retornam após concluir seus objetivos, a exemplo de Jekupé; outros, por não terem opção, precisam deslocar-se para a cidade para estudar.

[...] Vera teria de ir para a cidade grande, onde sempre acontecem acidentes, assaltos e mortes, como mostram as notícias dos jornais e da televisão. [...]

Vera vivia insistindo na idéia e seus pais acabaram concordando, mas sabiam que não seria fácil.

"Não temos dinheiro", pensava o pai. "Como vamos sustentá-lo?" (JEKUPÉ, 2006, p. 7).

Os personagens nas duas narrativas desejavam aprender a língua do não indígena. Semelhantemente a Vera, o personagem Karaí, de $O$ saci verdadeiro (JEKUPÉ, 2002), tem de sair da aldeia para aprender a ler e escrever em uma instituição não indígena. Ao INTERLETRAS, ISSN No 1807-1597. V. 9, Edição número 34. Outubro, 2021/ Março de 2022- p

Dossiê: Educação, infância, diversidade e ensino de língua em contexto complexo. 
conhecer a escrita, eles poderão percorrer o mesmo caminho de Jekupé (2002), e então divulgar a sua tradição por meio de histórias escritas por eles, que foram aprendidas na convivência com os seus parentes.

Nesse sentido, Rosa (2015b) dispõe que ao aprender o português, o indígena exerce a sua cidadania, pois a sua literatura escrita proporciona essa condição, a troca de conhecimentos. Vera aprendia com os colegas e também lhes ensinava um pouco sua cultura.

Ao chegar à escola, Vera iniciou um processo de interação com os colegas, vivenciando momentos de troca de saberes. O relacionamento com os não indígenas na escola é amistoso, embora seus colegas percebam que ele pertence à outra cultura e não o rejeitam. O menino é admirado pelos colegas da escola, os quais querem conhecer o seu mundo e, por isso, fazem-lhe perguntas sobre a sua aldeia, a língua guarani e desejam ouvir as histórias sobre seu povo. Nesse diálogo intercultural, o menino percebeu as desigualdades.

\footnotetext{
Seus amigos não-indígenas ficavam impressionados com a sua inteligência e ao verem ele, além de falar guarani, falava também português. Vera ensinava aos colegas as palavras que queriam saber em guarani.

- Como diz cachorro? - perguntavam.

- E bola?

- Como é casa?

Os garotos se encantavam com as histórias de Kunumi ou com as histórias que o menino havia aprendido com os mais velhos da aldeia. Contava como seu povo explicava a origem das coisas, do dia, da noite... (JEKUPÉ, 2006, p. 17-18).
}

$\mathrm{Na}$ aproximação com uma cultura diferente existe uma busca de interação e de uma aceitação das diferenças na forma de pensar e de viver que precisam ser respeitadas. No contato com a escola não indígena, com pessoas de outra comunidade, Vera passa a conhecer e adaptar-se aos costumes e hábitos diferentes, se mostra consciente disso e disposto a enfrentar as adversidades desse contato.

Conforme Rosa (2015a), isso permite perceber a dificuldade de um diálogo entre as culturas na convivência com a diversidade. Existe um diálogo multicultural nessa narrativa, uma intenção de abrir caminhos às multiplicidades, do trânsito das capacidades, da ampliação do ser e de sensibilidades. No entanto, o movimento de Vera entre a cidade e a aldeia pode ser um embate entre diversidade e identidade e, ao mesmo tempo, uma interação, em que as diferenças não o remetem a um processo de homogeneização, mas servem para aprendizagem do outro.

Muitas vezes, a discriminação e o preconceito com os indígenas no Brasil decorrem do fato de as pessoas não conhecerem a sua história verdadeira, pois sempre a ouviram sendo contada pela visão do colonizador. Nesse sentido, as narrativas indígenas desmentem a velha história relatada pelo Outro, ao trazer as narrativas contadas pelos seus ancestrais,

INTERLETRAS, ISSN $N^{\circ}$ 1807-1597. V. 9, Edição número 34. Outubro, 2021/ Março de 2022- p

Dossiê: Educação, infância, diversidade e ensino de língua em contexto complexo. 
tornando-os mais conhecidos e mostrando a possibilidade de uma interação entre os indígenas e não indígenas.

Segundo Graúna (2013), a falta de informação a respeito dos povos indígenas tem reforçado os preconceitos. A autora enfatiza que a escola e os programas de ensino poderiam contribuir mais para diminuir as desigualdades, ao valorizar a figura do indígena, como do negro, do mestiço e outros.

No entanto, Jekupé (2009) percebe o seu mundo com um olhar crítico, ao apresentar em sua obra um diálogo com o outro, valorizando uma educação para a diferença, sem que uma cultura se sobressaia, mas que aconteça de forma harmoniosa. Dessa maneira, é preciso apreender a importância dada à escola pelo autor, visto que foi o meio utilizado por Jekupé para tornar-se escritor, pois "sempre me preocupei muito com a questão da educação: é preciso escolas nas aldeias, porque é assim que surgirão os escritores. Se não souberem ler, nem escrever, continuarão sendo só contadores de histórias orais" (JEKUPÉ, 2009, p. 16).

As obras $O$ saci verdadeiro (2002) e Ajuda do Saci Kamba'i (2006), de Jekupé, refletem a sua aproximação com a escola, ao falar dos personagens em momentos de aprendizagem, na unidade de ensino, ouvindo histórias sendo narradas na aldeia pelos mais velhos e amigos. "Os personagens são, frequentemente, retratados em situações de aprendizagem, com um livro, ouvindo histórias e dialogando com os mais velhos e amigos" (LISBÔA, 2017, p. 69).

Vera vai para a cidade estudar e, nessa convivência com o diferente, constantemente tem sua identidade confrontada, desde o momento de sua chegada à escola, em seu primeiro dia de aula seus colegas percebem que ele é diferente. Esse modo de ver os indígenas, infelizmente, ainda ocorre na sociedade. Alguns os desprezam por não os conhecer, julgando-os inferiores. É necessário lutar contra conceitos errôneos sobre a presença do indígena na escola e na sociedade. Embora o autor demonstre uma relação de amizade entre indígenas e não indígenas, há conflitos e preconceitos muito presentes socialmente.

Dentre os conflitos enfrentados por Vera, existe algo que Jekupé (2006) apresenta nas "entrelinhas", como as dificuldades que ele passou, bem como ocorreu com outros indígenas, a fim de estudar, e o tempo que precisou ausentar-se de sua aldeia para isso.

Nos anos 1980 era raro ter escolas em aldeias e eu refletia muito sobre isso, pois acredito ser importante o índio estudar. E foi assim, observando nosso passado difícil e lembrando de alguns índios que conheci, que se mudaram para a cidade para estudar, que escrevi a história desse indiozinho que vocês acabaram de ler (JEKUPÉ, 2006).

As histórias de Vera e de Karaí se cruzam com a de Jekupé $(2002,2006)$ em alguns aspectos, tais como a vontade de estudar, de escrever histórias do seu povo e a dificuldade de acesso às escolas não indígenas e indígenas. $\mathrm{O}$ que inspirou o autor a escrever essa narrativa foi a sua experiência, baseando-se nas dificuldades vividas por ele nesse trânsito entre a aldeia e a cidade.

INTERLETRAS, ISSN No 1807-1597. V. 9, Edição número 34. Outubro, 2021/ Março de 2022- p

Dossiê: Educação, infância, diversidade e ensino de língua em contexto complexo. 
Em Ajuda do Saci Kamba'i (2006), o personagem percorre o espaço entre a aldeia e a cidade, trata dos desafios de Vera que, em sua busca, vai ao encontro do conhecimento dos jurua. Observa-se que a maior dificuldade que enfrenta nesse contato com um mundo diferente do seu é uma língua diferente da sua, o português.

A escola no território indígena tem sido importante para diminuir as dificuldades e problemas enfrentados pelos indígenas ao saírem de suas comunidades para adquirirem conhecimento da língua portuguesa e outros ensinamentos importantes. Ao mesmo tempo, a instituição escolar nesse espaço evidencia as desigualdades entre o indígena e o não indígena.

\footnotetext{
Nesse contexto, a escola na aldeia não é uma resposta ao modo de vida tradicional Guarani, mas uma estratégia de administrar a relação entre a aldeia e a cidade, propiciando às crianças indígenas a reflexão e a formação sobre os processos mais abrangentes que envolvem os índios Guaranis nas relações de desigualdade, constitutivas da sociedade brasileira (LISBÔA, 2015, p. 24).
}

Atualmente, já existem escolas nas aldeias do Brasil, e as histórias, além de serem contadas oralmente, podem ser escritas pelos indígenas, embora haja algumas áreas indígenas onde as unidades de ensino ainda não chegaram, e algumas crianças necessitam se deslocar de sua comunidade para ter acesso à educação.

Conforme Rosa (2014) existem aspectos positivos a serem observados, deixando clara a possibilidade de a literatura estar convocando essas vozes à valorização da identidade de seu povo. Desse modo, Jekupé $(2002,2003$, 2006,) busca o reconhecimento do povo Guarani também fora da aldeia. Existem narrativas que apresentam problemas atuais ou não, mas que são fatos vividos por esses sujeitos, permitindo ao leitor se reconhecer nos textos, que não estão apoiados apenas em sua estrutura formal, textual e linguística, mas mostram, além disso, a ideologia e cosmovisão no contexto da obra.

Jekupé (2002) externa que o convívio com o mundo do não indígena traz uma interação, mas pode também mostrar nessas relações as desigualdades, pelo desconhecimento destes das diferentes etnias e de seus saberes, podendo gerar conflitos. Em $O$ saci verdadeiro (2002), exibem-se situações em que há um confronto entre os diferentes conhecimentos, gerando preconceito, nesse sentido, ao falar do personagem Saci sendo negrinho, e este ter contato com o demônio pode externar indiretamente uma relação de inferioridade àqueles que possuem a cor da pele dissemelhante.

Quase todos os dias, Karaí ouvia histórias da sua mãe antes de deitar. Ouvia com atenção e sempre dizia:

- Mãe, quando eu tiver meus filhos, irei contar tudo a eles, assim como a senhora me conta (JEKUPÉ, 2002, p. 27).

Essa cena, característica de uma transmissão oral praticada pelos indígenas, se faz presente na narrativa enfatizando o valor dado à etnia Guarani e à sua ancestralidade, ao contar as histórias míticas de seu povo. Por meio dos relatos das histórias narradas por 
seus antepassados, avós, pais, Jekupé (2002) faz menção ao caráter oral desta Literatura nativa, como a história do Saci.

Jekupé (2002) faz referência a Monteiro Lobato para especificar que o personagem descrito por ele é da cultura Guarani. Com efeito, o escritor valoriza a sua história e o seu povo, ao trazer a existência de um Saci indígena. Na escola, Karaí ouve sua professora contar uma história sobre o Saci, porém, diferente da que sua mãe lhe contava.

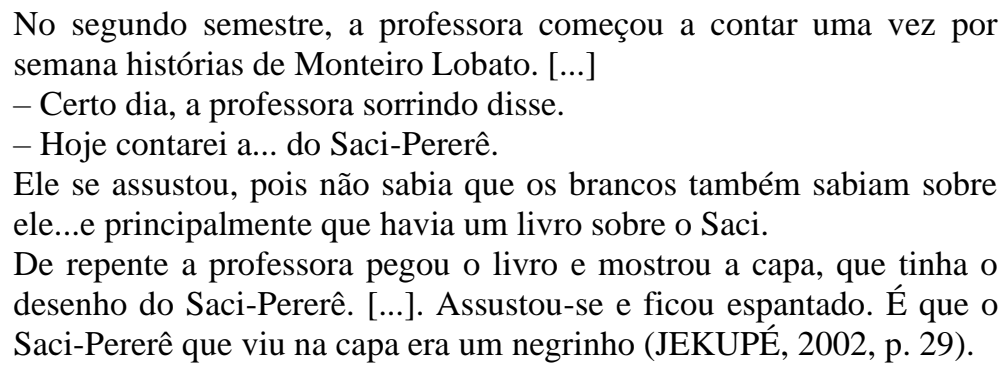

Nesse momento, o personagem Karaí descobre a existência de outra versão do Saci, fazendo com que ocorra um confronto entre diferentes mundos. De um lado está uma criança que se depara com o conhecimento da escola na figura da professora, que conta uma história e gera uma dúvida na cabeça do menino; do outro, a história contada por sua mãe, com o conhecimento ancestral aprendido em sua família, em diferentes gerações, mundos, saberes, sendo confrontados.

Para Rosa (2015a), o movimento de Vera entre a cidade e a aldeia pode ser um embate entre diversidade e identidade e, ao mesmo tempo, uma interação, em que as diferenças não os remetem a um processo de homogeneização, mas servem para aprendizagem do outro. Da mesma maneira aconteceu com Karaí, pois sua realidade foi confrontada, a dúvida foi instalada, então ele passa a duvidar dos ensinamentos recebidos na aldeia.

\footnotetext{
- Este Saci de quem eles falam é bem diferente e é mau, tem vários irmãos, nasce na taquara, assusta os outros e anda com cachimbo preto e uma carapuça vermelha na cabeça...

- Pois é, este não tem nada a ver com o nosso, o verdadeiro aquele de quem nossos antepassados sempre falaram (JEKUPÉ, 2002, p. 31).
}

O personagem Karaí aprende a conhecer o mundo do não indígena, mas precisa entender essas diferenças a fim de ampliar seus conhecimentos, não permitindo que estes sejam apagados nesse processo de aprendizagem na escola, por isso o confronto entre os modos diferentes de viver possibilita entender seu próprio mundo.

Para Graúna (2013), o Saci indígena caracteriza a formação de outro universo possível, por meio do diálogo, em que Karaí vai em busca de respostas para suas dúvidas e, ao encontrá-las, se reconhece convicto das verdades aprendidas. Destarte, essa narrativa ajuda a compreender o que se vive no presente mesmo em meio a desafios, exigindo de todos, independentemente do grupo a que pertence, o respeito à diversidade e à natureza. 
[...] a narrativa de Jekupé configura um espaço de liberdade para que o Saci indígena possa manifestar sua alteridade como protetor dos homens e das matas, ou como personagem que se identifica com quem se vê ou se sente diferente, ou até mesmo deslocado dentro ou fora da aldeia (GRAÚNA, 2013, p. 153).

A escola é esse lugar onde podem ser conhecidos diferentes mundos e, ao mesmo tempo, ela ensina sobre como podem contribuir para formar o patrimônio cultural do Brasil. Jekupé (2002) reconhece sua importância, bem como as suas limitações, e coloca isso em suas narrativas. As duas histórias com versões diferentes, uma apresenta um Saci indígena, e a outra um "negrinho" (JEKUPÉ, 2002, p. 30), ambas são importantes e merecem ter seu espaço. $O$ processo intercultural traz a novidade, não podendo ser usado como um motivo para preconceito e anulação do outro.

\section{CONSIDERAÇÕES FINAIS}

As narrativas nativas produzidas por escritores indígenas contribuem para o entendimento dos leitores infantojuvenis acerca dos povos originários, por possuírem valores, diferenças, semelhanças e experiências vivenciadas na vida real, além de nos ensinar a conviver melhor com o outro.

A escola como tema para os livros de Jekupé $(2002,2006)$ mostra a sua influência positiva pelo fato de nela se adquirir o conhecimento do "mundo dos juruas". O autor demonstra que é possível ao indígena, apesar das dificuldades, buscar conhecimento de outra cultura e, ao mesmo tempo, manter as suas memórias ancestrais.

As narrativas analisadas, $O$ saci verdadeiro (JEKUPÉ, 2002) e Ajuda do Saci Kamba'i (JEKUPÉ, 2006), permitiram refletir sobre as características da literatura nativa e conhecer mais os povos indígenas, ao relatar suas histórias e, por meio delas, perceber os obstáculos enfrentados por eles, com o intuito de manterem seus saberes vivos para as futuras gerações. Percebemos que as dificuldades existentes para os escritores nativos precisam ser rompidas, tais como preconceitos e estereótipos a respeito de seus conhecimentos e de sua literatura.

Para que isso acontecesse, inicialmente necessitaram se reinventar e entender o nome ou "apelido" que lhes foi dado pelo colonizador, "índio", e o que ele representava, para, então, assumi-lo a seu favor, em contextos de luta e de enfrentamento, e passaram a utilizá-lo em suas narrativas.

Desse modo, a literatura nativa tem revelado à sociedade o conhecimento das culturas nativas. Destaca-se que Jekupé (2002, 2006), em suas narrativas, escreve direcionado ao público infantojuvenil, ao apresentar a realidade do cotidiano vivido pelos indígenas no Brasil, seus dilemas, angústias e o desejo de obter o conhecimento do idioma e da escrita da língua portuguesa em um processo intercultural. Essas culturas, que anteriormente usavam apenas a prática da oralidade para transmitirem seus saberes ancestrais, se utilizam da escrita como uma forma de divulgação.

INTERLETRAS, ISSN $N^{\circ}$ 1807-1597. V. 9, Edição número 34. Outubro, 2021/ Março de 2022- p

Dossiê: Educação, infância, diversidade e ensino de língua em contexto complexo. 
As ações dos escritores indígenas contribuíram para garantir a eles a valorização e visibilidade de suas tradições, culturas, saberes, possibilitando o estabelecimento de uma literatura própria, pois escrevem em tom de crítica e denúncia, afirmando suas convicções e, assim, sinalizam aos povos que podem usar a escrita para se tornarem mais conhecidos.

Em linhas gerais, os textos da literatura nativa mostram as peculiaridades dos povos indígenas, por isso necessitam ser mais conhecidos na escola e tratados com mais respeito, pois há muitos preconceitos com relação à cultura e à realidade dessas pessoas. As obras de Jekupé, O saci verdadeiro (2002) e Ajuda do Saci Kamba'i (2006), trazem relatos da realidade vivida por seus personagens, que permitem reflexões acerca dos problemas a que estão sujeitos os povos originários no Brasil, devido à semelhança da literatura com a realidade.

Mesmo com suas especificidades, as narrativas analisadas têm em sua essência as vozes dos indígenas, antes subjugadas, a voz do Outro. Apesar de nelas expressar o convívio harmonioso com os juruás, ainda há conflitos no processo de interculturalidade nas escolas não indígenas.

\section{REFERÊNCIAS}

ALMEIDA, Maria Inês de; QUEIROZ, Sônia. Na captura da voz: as edições da narrativa oral no Brasil. Belo Horizonte: Autêntica, 2004.

BRASIL. Lei n. ${ }^{\mathbf{1}}$ 11.645, de 10 março de 2008. Altera a Lei n. ${ }^{\circ} 9.394$, de 20 de dezembro de 1996, modificada pela Lei n. $^{\circ} 10.639$, de 9 de janeiro de 2003. Disponível em: http://www.planalto.gov.br/ccivil_03/_Ato2007-2010/2008/Lei/L11645.htm. Acesso em: 12 mar. 2021.

DORRICO, Julie. A leitura da literatura indígena: para uma cartografia contemporânea. Revista Igarapé, Porto Velho, v. 5, n. 2, p. 107-137, 2018. Disponível em: https://www.periodicos.unir.br/index.php/igarape/article/view/2887. Acesso em: 30 mar. 2021.

DORRICO, Julie. Literatura infantojuvenil. Ouvir a diferença. Folha de São Paulo, São Paulo, 12020.2 Disponível em: https://quatrocincoum.folha.uol.com.br/br/artigos/literatura-infantojuvenil/ouvir-adiferenca. Acesso em: 13 mar. 2021.

GRAÚNA, Graça. Contrapontos da literatura indígena contemporânea no Brasil. Belo Horizonte: Mazza, 2013.

JEKUPÉ, Olívio. Ajuda do Saci Kamb’i. São Paulo: DCL, 2006.

JEKUPÉ, Olívio. Literatura escrita pelos povos indígenas. São Paulo: Scortecci, 2009. INTERLETRAS, ISSN $N^{\circ}$ 1807-1597. V. 9, Edição número 34. Outubro, 2021/ Março de 2022- p

Dossiê: Educação, infância, diversidade e ensino de língua em contexto complexo. 
JEKUPÉ, Olívio. Verá: o contador de histórias. São Paulo: Peirópolis, 2003.

JEKUPÉ, Olívio. O Saci verdadeiro. Londrina: EDUEL, 2002.

LISBÔA, Paulo Victor Albertoni. O escritor Jekupé e a literatura nativa. 2015. $122 \mathrm{f}$. Dissertação (Mestrado em Antropologia Social) - Universidade Estadual de Campinas, Campinas, 2015. Disponível em: http://repositorio.unicamp.br/bitstream/REPOSIP/279706/1/Lisbôa_PauloVictorAlberto ni_M.pdf. Acesso em: 12 mai. 2021.

LISBÔA, Paulo Victor Albertoni. Ocupar territórios imaginários: a narrativa ficcional de Olívio Jekupé. 2017. Tempo da ciência (UNIOESTE), v. 24, p. 68-75, Disponível em:

http://e-revista.unioeste.br/index.php/tempodaciencia/article/view/17906. Acesso em: 20 de abr. 2021

MANCINI, Ana Paula Gomes; TROQUEZ, Marta Coelho Castro. Desconstruindo estereótipos: apontamentos em prol de uma prática educativa comprometida eticamente com a temática indígena. Tellus, Campo Grande, ano 9, n. 16, p. 181-206, jan./jun. 2009. Disponível em: https://www.tellus.ucdb.br/tellus/article/view/185/212. Acesso em: 18 mai. 2021.

MINDLIN, Betty. Prefácio. In: JEKUPÉ, Olívio. O Saci verdadeiro. Londrina: EDUEL, 2002. p. 9-13.

ROSA, Francis Mary Soares Correia. Espelho de duas faces: a literatura indígena de Olívio Jekupé na produção de alteridades sobre o não-índio. Revista Crioula, São Paulo, n. $14, \quad$ p. 10-22, 2014. Disponível em: https://www.revistas.usp.br/crioula/article/view/75943. Acesso em: 18 mai. 2021.

ROSA, Francis Mary Soares Correia. Kamba'i: ensaio sobre o uso da literatura indígena para uma educação intercultural. Revista Temas em Educação, [S. l.], v. 24, n. 2, p. 167178, jul./dez. 2015a. Disponível em: https://periodicos.ufpb.br/index.php/rteo/article/view/23728. Acesso em: 18 mai. 2021.

ROSA, Francis Mary Soares Correia. O papel da literatura nativa na construção de uma identidade étnico literária no pós-indianismo. Revista Crioula, São Paulo, n. 15, 2015b. Disponível em: https://doi.org/10.11606/issn.1981-7169.crioula.2015.85950. Acesso em: 6 abr. 2021. 
* Professora, Doutora do Programa de Pós-graduação Mestrado em Letras da Faculdade de Comunicação, Artes e Letras, da Universidade Federal da Grande Dourados (UFGD). https://orcid.org/0000-0002-2046$\underline{7244}$

** Mestra em Letras pelo Programa de Pós-graduação Mestrado em Letras da Faculdade de Comunicação, Artes e Letras, da Universidade Federal da Grande Dourados (UFGD). https://orcid.org/0000-0001-8750$\underline{7995}$ 